\title{
Long-term experimental manipulation of moisture conditions and its impact on moss-living tardigrades
}

\author{
K. Ingemar JÖNSSON
}

Department of Mathematics and Science, Kristianstad University, SE-291 88 Kristianstad, Sweden

e-mail: ingemar.jonsson@mna.hkr.se

\begin{abstract}
The effects of long-term experimentally modified hydration conditions on populations of moss-living tardigrades were investigated in a naturally dry South-Swedish alvar environment at the Island Öland. Carbonite rocks with mosses were collected from rock fences and arranged in three experimental groups: increased dehydration, increased hydration, and control. The total experimental period was 18 months, with treatments applied during two 6 month periods. The density of tardigrade populations was recorded. The total population of tardigrades, all species included, tended to be lower under watering treatment, but the difference was only marginally significant. Populations of Richtersius coronifer and Echiniscus spiniger did not respond to the treatments, while populations of Milnesium tardigradum declined under conditions of increased hydration. The density of eggs in $\mathrm{R}$. coronifer was also lower in the watering treatment. Thus, no positive response to increased hydration was recorded. These results suggest that the tardigrade populations either were not limited by the amount of hydrated periods, or that some other factor(s) counteracted the expected positive response to increased hydration. All populations showed a high variability in density among different moss samples, and the rock from which a sample was taken explained a significant part of this variability. This confirms a commonly believed, but seldom quantified, high heterogeneity in density of semi-terrestrial tardigrades, also among seemingly very similar substrates.
\end{abstract}

Key words: tardigrades, desiccation, population change, Richtersius coronifer, Milnesium tardigradum, Echiniscus spiniger

\section{INTRODUCTION}

Tardigrades represent an important component of the biota in terrestrial microhabitats exposed to recurrent desiccation, including mosses and lichens growing on exposed substrates such as rocks and tree trunks. Although being aquatic organisms, tardigrades living in these habitats have evolved the ability to tolerate desiccation by entering a dehydrated state called anhydrobiosis (Wright et al. 1992). During anhydrobiosis the animal is metabolically inactive, and body growth, reproduction, and therefore population growth is arrested. Factors regulating the dynamics of semi-terrestrial tardigrade populations are poorly understood, but it is well established that many populations vary in a cyclical pattern over the year, often with density peaks in spring and / or autumn (Kinchin 1994). Earlier studies have shown significant relationships between population density and food availability (e.g., Hallas \& Yeates 1972) and factors such as temperature and humidity (e.g., Franceschi et al. 1962-1963; Morgan 1977; Wright 1991).

Because of their dependence on water to maintain an active life, one would perhaps expect tardigrades to be more abundant in wet substrates than in dry ones. However, exactly the opposite pattern has been reported, i.e., higher tardigrade densities in sun-exposed substrates than in shaded ones (Ramazzotti \& Maucci 1983; Kinchin 1992, 1994). Despite the potential implications for population dynamics and evolutionary processes in tardigrades, few explanations for this pattern are found in the literature.

High densities of desiccation-tolerant organisms in dry habitats could reflect a trade-off between competitiveness and desiccation tolerance (Alpert 2006), such that desiccation tolerant populations are released from non-desiccation tolerant competitors in the dry habitats. Kinchin (1992, 1994) discussed the possibility that drying out of the substrate may be positive for tardigrade populations by reducing the density of fungi in the substrate. Fungi, which grow better under wet conditions, may have several negative effects on tardigrades, including reduced ability to move around in the substrate, and infections by parasitic fungi on the body of tardigrades (Kinchin 1994). Two species of mossliving hyphomycetes fungi capturing rotifers and tardigrades were described by Barron et al. (1990). Wet substrates may also have more competitors and predators of tardigrades in general, including various arthropods (e.g., mites, springtails), nematodes, rotifers and other tardigrades. Many of these species may not survive in a dry substrate, and may die or disperse actively from the substrate when it starts to dry out. Thus, tardigrades could be more common in dry habitats because of the inability of some of their potential competitors and predators to maintain populations under dry conditions. However, these benefits for tardigrades should be weighed against the lower rate of reproduction that a dry substrate imposes. Periods of anhydrobiosis are 
unproductive and increase the generation time of tardigrades. The best substrate for tardigrades may then be one that dries out frequently, but for short periods only, providing tardigrades and other anhydrobiotic organisms with favourable periods of reduced competition or predation. Studies by Hofmann (1987) tend to support this prediction, with a generally higher number of tardigrade species found in moss habitats which "dry out frequently and receive direct sunlight regularly", compared to more permanently moist or dry moss substrates.

Contrary to the view that competition and predation may explain high densities of tardigrades in dry habitats, Pilato (1979) considered both intra- and inter-specific competition to be unimportant in the evolution of tardigrade life histories, and instead suggested that abiotic factors such as humidity, temperature and oxygen supply are more important. Experimental studies manipulating the frequency of dry periods would be a first step towards an understanding of both the general population dynamics of anhydrobiotic tardigrade populations, and of the often high densities of tardigrades found in dry microhabitats.

In the current study, the effects of different humidity conditions on moss-living tardigrade populations over a period of 18 months were evaluated, by experimental induction of drier or wetter conditions than normal.

\section{METHODS}

\subsection{Experimental setup}

The experiment was made at the Ecological Research Station of Uppsala University (16 $36^{\circ} 5.9^{\prime \prime} \mathrm{E}$, $56^{\circ} 37^{\prime} 9.6^{\prime \prime} \mathrm{N}$ ), situated at Ölands Skogsby on the Baltic Sea Island Öland. Twenty-four pieces of carbonite rock (size approximately $40 \times 30 \mathrm{~cm}$ ) with mosses (mainly Orthotrichum cupulatum Hoffman ex Bridel, 1801) were collected from rock fences at the alvar environment Stora Alvaret and transferred to the Ecological Station at the North-Western edge of the alvar area. These mosses grow directly on the bare rock, and there is practically no water-holding capacity of the moss substratum (Fig. 1a). The 24 collected rocks were distributed among three experimental treatment groups (8 rocks/treatment): i) increased hydration ( $\mathrm{W}=$ watering treatment), ii) reduced hydration ( $\mathrm{D}=$ dehydration treatment), and iii) natural hydration $(\mathrm{C}=$ control). This resulted in a nested experimental design, where rock level was nested under treatment level. The rocks were placed on three experimental tables (size $c a 2 \times 1 \mathrm{~m}$ ), one for each treatment group (Fig. 1b). The height of the tables above ground was $c a 1 \mathrm{~m}$, similar to the height of the fence from which the rocks were collected.

Experimental treatments were run during two time periods: 26 April - 6 November 2000 and 30 April - 30 October 2001. In between these treatment periods all samples were exposed to natural conditions. The interruption in treatment during the winter period was due to the frost conditions that would interfere with the experimental treatments.
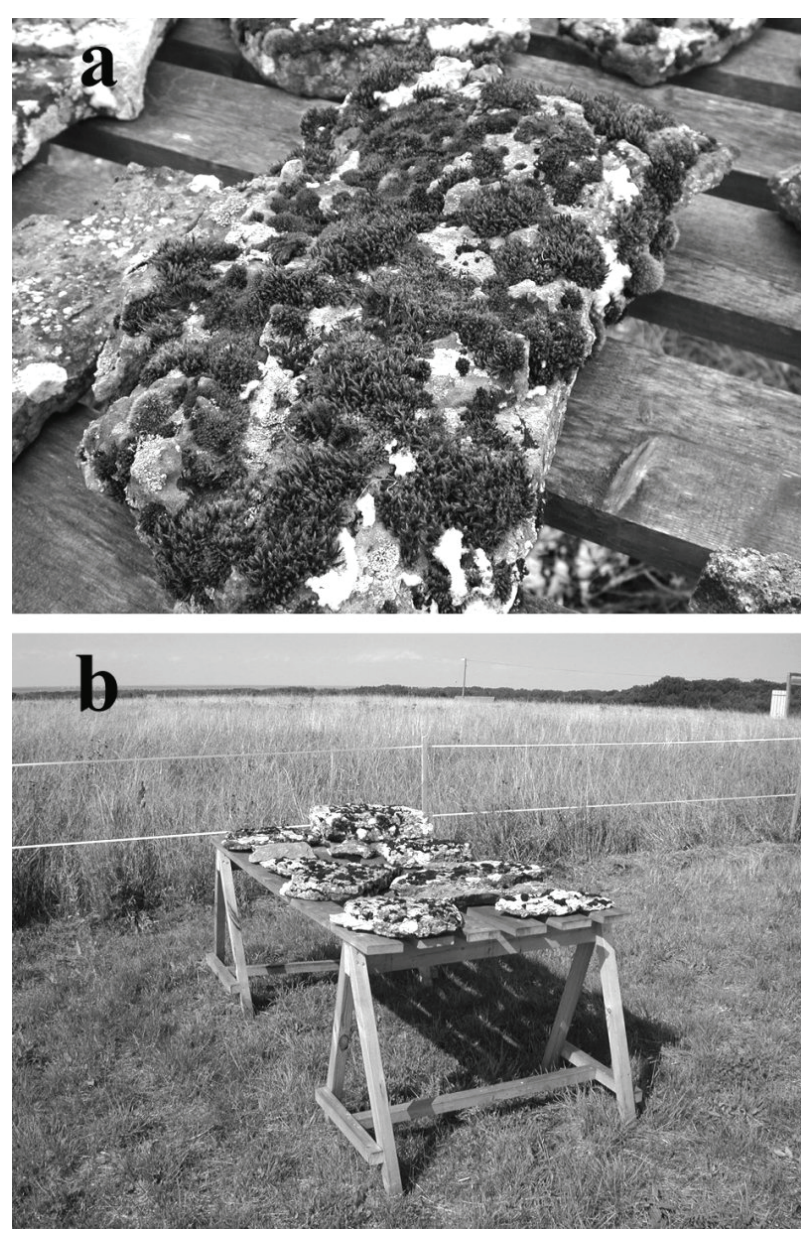

Fig. 1. Photographs of the experimental setup. a: Carbonite rock with mosses. b: One of the experimental tables with rocks. Photo: K. Ingemar Jönsson.

In the watering treatment, an automatic programme was run five days per week, when samples were watered (using tap water) for 10 minutes every second hour between 08.00 and 18.00 (i.e., six times). The watering of each 10-minute period represented a precipitation of $1.5 \mathrm{~mm}$, or $40 \mathrm{~mm}$ per week, in total $1152 \mathrm{~mm}$ and 1188 $\mathrm{mm}$ over the whole experimental period in 2000 and 2001, respectively. The watering treatment samples were also exposed to natural precipitation during the experimental periods $(303 \mathrm{~mm}$ in $2000,359 \mathrm{~mm}$ in 2001), so in some days natural precipitation and watering treatment overlapped. Compiling the natural and artificial precipitation by i) adding natural precipitation in non-experimental days ( 2 days per week) to the artificial precipitation (5 days per week), and ii) replacing the daily artificial precipitation value $(9 \mathrm{~mm})$ with the natural precipitation value in days when the latter exceeded the former, total precipitation of watering treatment samples was estimated as $1254 \mathrm{~mm}$ in year 2000 and $1366 \mathrm{~mm}$ in year 2001. Comparing these 
Tab. 1. Average density (animals (eggs) $\mathrm{g}^{-1}$ dry moss) of all tardigrades and of specific taxa in the reference samples (rocks pooled). $\mathrm{N}=192$ samples of moss.

\begin{tabular}{lccc}
\hline Species & Average density & Min - Max & SD \\
\hline All tardigrades & 255.4 & $19.9-893.6$ & 163.0 \\
Richtersius coronifer & 99.6 & $0-455.6$ & 94.7 \\
Echiniscus spiniger & 6.0 & $0-312.2$ & 25.3 \\
Milnesium tardigradum & 1.9 & $0-45.6$ & 5.4 \\
Eutardigrada spp. & 147.9 & $6.6-827.6$ & 124.7 \\
Richtersius coronifer eggs & 315.3 & $0-2691.1$ & 337.4 \\
\hline
\end{tabular}

estimates with the natural precipitation, watering treatment samples thus received about 4 times more precipitation than the control samples.

The dehydration treatment was set-up by placing a transparent plastic cover over the experimental table continuously during 5 days (from 8 am in day 1 to $4 \mathrm{pm}$ in day 5), every second week. This procedure represented an average reduction of the natural precipitation by $31 \%$ (rainfall prevented 104 hours out of 336 during a two-week period).

\subsection{Sampling and extraction}

Reference (pre-experimental) samples were collected on the 20 April 2000 and post-experimental samples on the 10 November 2001. From each rock, eight random pieces of moss were collected. The samples represented a mixture of spatially well defined small cushions and pieces from larger cushions. The samples were dried and kept frozen $\left(-20^{\circ} \mathrm{C}\right)$ until rehydration and extraction of tardigrades. Before extraction of tardigrades, the dry moss samples were weighed on a Mettler HK60 balance to the nearest mg. All 8 samples/rock from the reference sampling were analyzed, while only 6 samples/rock from the post-experimental sampling were analyzed. The average dry weight of reference moss samples was $0.28 \mathrm{~g}(0.075-0.68 \mathrm{~g}, \mathrm{SD}=0.12, \mathrm{~N}=$ 192), and of post-experimental samples $0.23 \mathrm{~g}(0.11-$ $0.37, \mathrm{SD}=0.058, \mathrm{~N}=144$ ).

After rehydration of moss samples over night, tardigrades were extracted from the moss by sieves ( 250 and $40 \mu \mathrm{m}$ mesh size) under running tap water. Individual tardigrades and eggs (Richtersius coronifer (Richters, 1903 ) only) were then collected with a Pasteur pipette and counted. Both dead and alive specimens were recorded.

\subsection{Species determination}

Extracted specimens were taxonomically separated under stereo microscope. Specimens of $R$. coronifer, Milnesium tardigradum (Doyère, 1840) and Echiniscus spiniger Richters, 1904 (identification by G. Pilato) were identified. In addition, high densities of unidentified eutardigrades were also present in the samples. Previous observations have shown that most of these eutardigrades belong to the Macrobiotus cf. hufelandi complex, including the species Macrobiotus terminalis Bertolani and Rebecchi, 1993 and Macrobiotus macro- calix Bertolani and Rebecchi, 1993 (R. Guidetti, personal communication). However, since other species may also be present and identification to species level of these specimens could not be done by stereo microscope, these eutardigrades were not analyzed as a separate taxonomic group for treatment effects on population density. However, in the analysis of total tardigrade population density, the unspecified eutardigrades were included.

\subsection{Statistical analysis}

Analyses of variance were made using the GLM (nested ANOVA), ANOVA (one-way ANOVA), and non-parametrics (Kruskal-Wallis Analyses of Variance) modules of SYSTAT (v. 11.0, SYSTAT Software Inc., 2004). Because of the nested structure of the experimental design (rock replicates nested under treatment) nested ANOVA was used to analyze variations among reference samples, before application of treatments. Due to heterogeneity of initial conditions and significant effects of rock (implying non-independence of samples within treatment groups, see Results) the evaluation of treatment effects had to take into account both the preexperimental reference data as well as the post-experimental data, and use rock as within-treatment replicate level. Among several possible ways to statistically analyze treatment effects of a pretest/posttest data structure (see, e.g., Bonate 2000), I used difference scores of population change within rock as the dependent variable (mean post-experimental density - mean reference density), and analyzed treatment effects by one-way ANOVA. In cases where the assumptions for parametric tests were not met by data, Kruskal-Wallis analysis of variance was used instead of one-way ANOVA. Nonparametric variance analyses with only two groups in the categorical variable are reported as Mann-Whitney U-test. Due to the presence of zero and negative values, data were not transformed before analyses. All statistical tests were two-tailed.

\section{RESULTS}

\subsection{Treatment responses of the total population of tardigrades}

The mean total density of tardigrades (all specimens included) in the reference samples are given in table 1. Mean density in the reference samples did not differ 


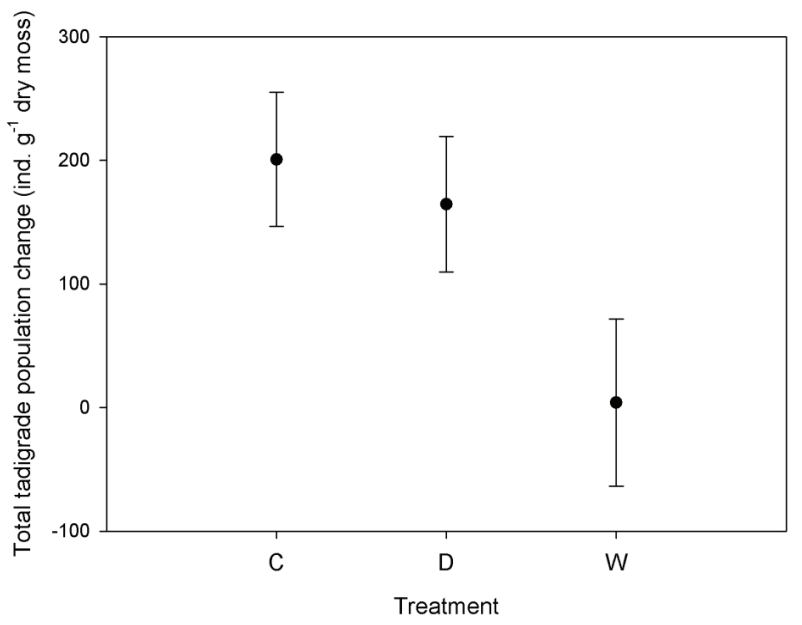

Fig. 2. Mean change in total tardigrade population density (with one SE, all tardigrade specimens included) over the experimental period, for different treatment groups. $\mathrm{C}=$ controls, $\mathrm{D}=$ dehydration treatment, $\mathrm{W}=$ watering treatment. Each estimate represents the mean density for 8 rock estimates, each of which in turn were based on 8 (reference) or 6 (post-experimental) samples of moss per rock.

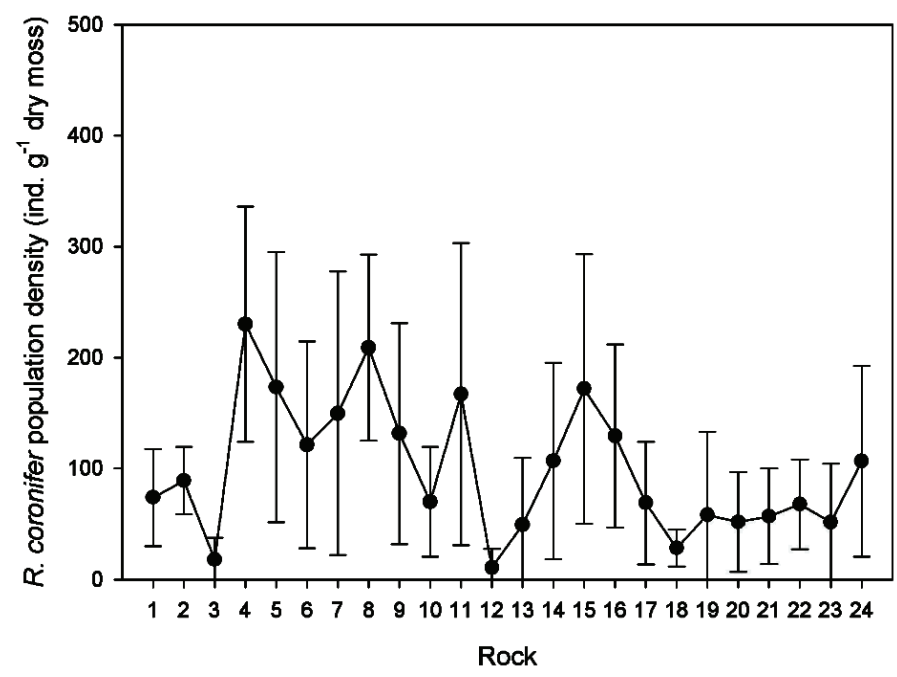

Fig. 3. Mean population density (with one SE) of Richtersius coronifer in the different rocks of reference samples, collected before application of the experimental treatments. Rocks 1-8 were used in the control group, 9-16 in the watering treatment group, and 1724 in the dehydration treatment group. Each rock estimate represents the mean of 8 samples of moss.

among the treatment groups (Nested ANOVA, $F$ $=1.30(2 / 168), P=0.28)$, but variation among rocks explained a significant part of the variation $(F=$ $3.10(21 / 168), P<0.001)$. One-way ANOVA analysis on the change in population density within rock from reference sampling to post-experimental sampling (using rock as replicate) revealed a marginally significant effect of treatment $(F=3.13(2 / 21), P=0.065)$, with low densities in the watering treatment group (Fig. 2). Thus, there was an indication that watering treatment may have had a negative impact on the tardigrade populations.

\subsection{Treatment responses in population density for different tardigrade species}

The mean densities of different tardigrade species in the reference samples are given in table 1. A nested
ANOVA (rock nested under treatment group) revealed a significant difference in mean population densities of reference samples among the three treatment groups in both $M$. tardigradum $(F=3.78(2 / 168), P=0.025)$ and $R$. coronifer $(F=13.36(2 / 168), P<0.001)$. This was also the case for $R$. coronifer egg density $(F=$ 12.39(2/168), $P<0.001)$. There was no such difference for $E$. spiniger $(F=1.086(2 / 168), P=0.34)$. The same analysis also revealed, in all species and in $R$. coronifer eggs, a significant variation among rocks in population density ( $M$. tardigradum: $F=7.92(21 / 168), P<0.001$; $R$. coronifer: $F=3.79(21 / 168), P<0.001 ;$ E spiniger: $F$ $=1.63(21 / 168), P=0.047 ; R$. coronifer eggs: $F=$ 7.16(21/168), $P<0.001$; Fig. 3 shows variation for $R$. coronifer). The standard errors in figure 3 also indicate a very large variation in population density among sam- 
Tab. 2. Mean change in population density (animals (eggs) $\mathrm{g}^{-1}$ dry moss) over the experimental treatment period, for different treatments and tardigrade taxa. $\mathrm{N}=8$ for all treatment groups.

\begin{tabular}{|c|c|c|c|c|c|c|}
\hline \multirow[t]{2}{*}{ Species } & \multicolumn{2}{|c|}{ Control } & \multicolumn{2}{|c|}{ Watering } & \multicolumn{2}{|c|}{ Dehydration } \\
\hline & Mean & SD & Mean & SD & Mean & SD \\
\hline Richtersius coronifer & 133.7 & 133.6 & 107.6 & 120.5 & 113.6 & 106.0 \\
\hline Echiniscus spiniger & 4.7 & 8.3 & 14.9 & 19.1 & 10.7 & 45.4 \\
\hline Milnesium tardigradum & 4.3 & 10.9 & -1.7 & 1.7 & 2.9 & 8.1 \\
\hline Richtersius coronifer eggs & 36.9 & 441.8 & -175.2 & 138.3 & 300.0 & 337.4 \\
\hline
\end{tabular}

ples within each rock. Thus, these tardigrade populations show a high small-scale heterogeneity in population density.

Experimental treatment affected the population change over the experimental period significantly in $M$. tardigradum (Kruskal Wallis: $K W=9.33, d f=2, P=$ 0.009; Tab. 2), with samples from the watering treatment showing a significant decline in population density compared to the control (Mann-Whitney: $U=55.0, d f=$ $1, P=0.014)$, and dehydration treatment samples $(U=$ 55.0, $P=0.008)$, while controls and dehydration treatment did not differ $(U=42.0, P=0.26)$. In $R$. coronifer and $E$. spiniger there were no effect of treatment on population density $(R$. coronifer: $F=0.10(2 / 21), d f=2$, $P=0.90 ;$ E. spiniger: $K W=2.80, d f=2, P=0.25$; Tab. 2).

Experimental treatment affected the change in egg density over the experimental period in $R$. coronifer significantly $(F=4.15(2 / 21), P=0.030$; Tab. 2$)$. Egg density declined under watering treatment and this change differed significantly compared to the dehydration treatment (Tukey-test: $P=0.024$ ), while there was no significant difference between the control and the dehydration (Tukey-test: $P=0.27$ ) or watering (Tukeytest: $P=0.42$ ) treatment.

\section{DISCUSSION}

The current experiment showed a weak marginally significant tendency towards a negative effect of increased hydration on the total population of tardigrades, while specific tardigrade taxa showed diverging responses. The populations of Richtersius coronifer and Echiniscus spiniger were not affected by the treatments, while populations of $M$. tardigradum declined under the watering treatment. However, M. tardigradum represented a small proportion of the total population of tardigrades in these samples, and the main factor behind the observed decline in total population density under watering treatment was instead the unspecified eutardigrades. A positive response in population density to increased hydration would be expected if a population is in a density-independent phase where hydration frequency limits growth. The population density would then increase due to a higher growth per time unit. Increased hydration should also lead to a higher primary production of the substrate, thereby providing more food resources for tardigrade populations, both directly (more food for plant and algae feeding tardigrades) and indirectly (more food for tardigrades feeding on primary consumers such as unicellular organisms and other metazoans). This should also favour higher tardigrade densities. However, none of the populations in this study responded positively to the watering treatment. On the contrary, total tardigrade density tended to decline, and populations of one of the tardigrade species declined significantly. This seems to suggest that these populations were not limited by the amount of hydration conditions, or that some other factor(s) counteracted the expected positive response.

Perturbations in hydration conditions could influence the role of competition, predation, and parasitism, by affecting organisms other than a given tardigrade species. Oribatid mites have been mentioned as potential predators on tardigrades (Kinchin 1994), but were very rare in the present samples, found in only 5 of the reference and 5 of the post-experimental samples (previous experience suggest that the extraction method used here for tardigrades is effective also for oribatid mites. However, other predatory arthropods may have escaped the extraction and could have influenced the results). Fungi have been proposed as another factor that could induce negative effects on tardigrades under more permanently hydrated conditions (Kinchin 1994). For instance, Morgan (1977) reported a negative correlation between population density and rainfall up to one month before sample collection in Macrobiotus hufelandi Schultze, 1834 and in the heterotardigrade Echiniscus testudo (Doyère, 1840) and suggested that high humidity could promote fungal attacks on tardigrade eggs and juveniles. Both effects of fungal mycelium on tardigrade movements, and more direct attacks of fungal parasites could affect tardigrade populations (Kinchin 1994; Barron et al. 1990). In the current study, effects of fungi were not evaluated, but it seems unlikely that fungi would explain the negative population development in $M$. tardigradum, since one would expect similar effects on all tardigrade species.

A possible reason for observed taxonomic differences in responses to treatments could be that watering and dehydration treatments affected the seasonal patterns of growth and reproduction in these tardigrade populations differently. If population density under natural conditions stays relatively constant over time, effects of treatments should be easy to detect, regardless of when during the year the population is monitored. On the other hand, if populations fluctuate substantially over time, perturbed hydration conditions could bring 
the population out of phase with the control population. Such effect could explain the reduced density of $R$. coronifer eggs under watering treatment. Interestingly, $M$. tardigradum was the only specific tardigrade where a response to the treatments was observed, and Schuetz (1987) did not find any seasonal variation in population density of this species. This may indicate that the natural population dynamics of the different tardigrade species influenced the observed results of treatment effects, but yearly dynamics of the current tardigrade populations have not yet been described. Several studies on the temporal pattern of tardigrade populations have been published (reviewed by Kinchin 1994). In M. hufelandi, now recognized as a species complex containing several different species (Bertolani \& Rebecchi 1993), population peaks have been documented in both spring and autumn (Morgan 1977; Hallas \& Yeates 1972; Kinchin 1985). Moreover, Morgan (1977) reported evidence of more long-term cycles in population dynamics in $M$. hufelandi, superimposed on the annual cycles and ranging over several years.

Few other experimental studies have investigated the effects on tardigrade populations of artificially increased hydration conditions. However, in a study on soil fauna Briones et al. (1997) evaluated the effect of experimentally increased rainfall (during ca 3 months) on tardigrades (with no species discrimination). No significant response was observed, but population density tended to be relatively low in samples receiving extra rainfall. Briones et al. (1997) suggested that oxygen deficiency may have contributed to the low abundance of tardigrades in soils receiving additional water. Since two of the tardigrade species in the current study did not decline in density it seems unlikely that oxygen deficiency was involved in the reduced density of M. tardigradum.

A number of studies have investigated the effect of irrigation on nematode densities in soils. These are of some interest here, because nematodes represent one of the preys of predatory tardigrades. Freckman et al. (1987) reported that densities of total nematodes, fungivores, bacterivores, and omnivores were not affected by long-term irrigation treatment (one year), while the density of phytophage nematodes increased. In a more short-term study, Steinberger \& Sarig (1993) showed that total nematode density increased significantly after single bouts of irrigation, and that density increased with the amount of added water. Fungal- and bacterial-feeding nematodes were the main groups responsible for this increase. Also Schnürer et al. (1986) recorded increased numbers of nematodes after irrigation and natural rain fall, but attributed this effect to activation of anhydrobiotic animals rather than representing a growth in the population. In the present study, nematodes of the genus Chiloplectus (feeding on bacteria or algae) and Prionchulus (predatory) were abundant in the moss samples but their densities were not recorded. These are likely preys to $M$. tardigradum which is a known predator on nematodes, rotifers, and protozoa. Among the other tardigrade species in the present study, $R$. coronifer seems to feed on various algae (Schill, Jönsson \& Nebel, unpublished), while no information is available on the diet of E. spiniger. However, according to Ramazzotti \& Maucci (1983), moss-living heterotardigrades feed exclusively on plant material.

The pre-experimental reference sampling documented a large variation in population density among different moss samples, especially connected with different rocks. This is in line with previous studies (Nelson 2002; Meyer 2006). In the Öland study site, these differences cannot realistically be related to macro- or microclimatic conditions, since all mosses grow on the same kind of substrate, carbonite rock, and are exposed to the same climatic conditions. The strong effect of rock could arise from either historical factors, such as time since establishment, or from a lack of synchrony in population dynamics among rocks. A high dispersal ability of moss-living tardigrades among nearby substrates would counteract these factors, and the observed among-rock variability therefore suggests that dispersal ability is very limited. The factors underlying population variability and dynamics in tardigrades is largely unknown and clearly deserve more investigations.

\section{CONCLUSIONS}

The current study is the first experimental investigation into the effect of changed humidity conditions on specific tardigrade populations. The results seem to suggest that different tardigrade species respond differently to increased hydration, and increased hydration did not promote populations growth in any of the recorded species. The fact that the species that showed declined populations under increased hydration is carnivorous raises questions about effects of watering on its prey populations. Since the resolution of the experimental response is relatively low (e.g., no analysis of age-structure or continuous population dynamics) this investigation should be considered a pilot study and a starting point for more in depth experiments. With the restriction that the animals in each subsample can only be monitored once, moss-living tardigrades seems to be ideal for experimental studies of population dynamics and the role of periods of desiccation in anhydrobiotic organisms.

\section{ACKNOWLEDGEMENTS}

I am very grateful to the Ecological Research Station at Ölands Skogsby for allowing me to set up the experiment, and especially to Lennart Ågren for continuous help during the experiment. I am also very grateful to G. Pilato for the identification of E. spiniger. I also thank two anonymous referees for useful comments. Permission for collection of rocks from Stora Alvaret was provided by the County Administrative 
Board, Kalmar. The study was supported by the Swedish Science Council.

\section{REFERENCES}

Alpert, P. 2006. Constraints of tolerance: why are desiccationtolerant organisms so small or rare? J. Exp. Biol., 209: $1575-1584$

Barron, G.L., C. Morikawa \& M. Saikawa. 1990. New Cephaliophora species capturing rotifers and tardigrades. Can. J. Bot., 68: 685-690.

Bertolani, R. \& L. Rebecchi. 1993. A revision of the Macrobiotus hufelandi group (Tardigrada, Macrobiotidae), with some observations on the taxonomic characters of eutardigrades. Zool. Scripta, 22: 127-152.

Bonate, P.L. 2000. Analysis of pretest-posttest designs. Chapman \& Hall/CRC, London: 205 pp.

Briones, M.J.I., P. Ineson \& T.G. Piearce. 1997. Effects of climate change on soil fauna; responses of enchytraeids, Diptera larvae and tardigrades in a transplant experiment. Appl. Soil Ecol., 6: 117-134.

Franceschi, T., M.L. Loi \& R. Pierantoni. 1962-1963. Risultati di una prima indagine ecologica condotta su popolazioni di Tardigradi. Boll. Mus. Ist. Biol. Univ. Genova, 32: 69-93.

Freckman, D.W., W.G. Whitford \& Y. Steinberger. 1987. Effect of irrigation on nematode population dynamics and activity in desert soils. Biol. Fertil. Soils, 3: 3-10.

Hallas, T.E. \& G.W. Yeates. 1972. Tardigrada of the soil and litter of a Danish beech forest. Pedobiologia, 12: 287-304.

Hofman, I. 1987. Habitat preference of the most frequent moss-living Tardigrada in the area of Giessen (Hessen). In: R. Bertolani (Ed.), Biology of Tardigrades. Selected Symposia and Monographs U.Z.I., 1. Mucchi Editore, Modena, Italy: 211-216.

Kinchin, I.M. 1985. Notes on the population dynamics of Macrobiotus hufelandi (Tardigrada). Microscopy Bull., 7 : 4-6.
Kinchin, I.M. 1992. An introduction to the invertebrate microfauna associated with mosses and lichens with observations from maritime lichens on the West coast of the British Isles. Microscopy (London), 36: 721-731.

Kinchin I.M. 1994. The Biology of Tardigrades. Portland Press, London: 186 pp.

Meyer, H.A. 2006. Small-scale spatial distribution variability in terrestrial tardigrade populations. Hydrobiologia, 558: 133-139.

Morgan, C.I. 1977. Population dynamics of two species of tardigrade, Macrobiotus hufelandi (Schultze) and Echiniscus (Echiniscus) testudo (Doyère), in roof moss from Swansea. J. Anim. Ecol., 46: 263-279.

Nelson, D.R. 2002. Current status of the Tardigrada: Evolution and Ecology. Integr. Comp. Biol., 42: 652-659.

Pilato, G. 1979. Correlations between cryptobiosis and other biological characteristics in some soil animals. Boll. Zool., 46: 319-332.

Ramazzotti, G. \& W. Maucci. 1983. Il Phylum Tardigrada. III edizione riveduta e corretta. Mem. Ist. ital. Idrobiol., 41: $1-1012$.

Schnürer, J., M. Clarholm, S. Boström \& T. Rosswall. 1986. Effects of moisture on soil microorganisms and nematodes: a field experiment. Microb. Ecol., 12: 217-230.

Schuetz, G. 1987. A one-year study on the population dynamics of Milnesium tardigradum Doyère in the lichen Xantoria parietina (L.) Th. Fr. In: R. Bertolani (Ed.), Biology of Tardigrades. Selected Symposia and Monographs U.Z.I., 1. Mucchi Editore, Modena, Italy: 217-228.

Steinberger, Y. \& S. Sarig. 1993. Response by soil nematode populations and the soil microbial biomass to a rain episode in the hot, dry Negev Desert. Biol. Fertil. Soils, 16: 188-192.

Wright, J.C. 1991. The significance of four xeric parameters in the ecology of terrestrial Tardigrada. J. Zool., 224: 59-77.

Wright, J.C., P. Westh \& H. Ramløv. 1992. Cryptobiosis in Tardigrada. Biol. Rev., 67: 1-29. 